\title{
Numerical Simulation of Nonlinear Oil Film Forces of Tilting-Pad Guide Bearing in Large Hydro-unit
}

\author{
LI-FENG MA $^{\mathrm{a}, *}$ and XIN-ZHI ZHANG ${ }^{\mathrm{b}}$ \\ a School of Civil Engineering and Mechanics, Xi'an Jiaotong University, 710049, P.R. China, \\ ${ }^{\mathrm{b}}$ Zhengzhou Research Institute of Mechanics Engineering, 450052, P.R. China
}

(Received 24 November 1998; In final form 29 January 1999)

\begin{abstract}
A new numerical method is proposed for predicting the nonlinearity of tilting-pad guide bearing oilfilm force in the rotor-bearing system in a large hydro-unit. Nonlinear displacement and velocity of the journal center, as well as nonlinear tilting angles and angular velocities of the pads in non-stationary Reynolds equation are taken into account. This method is also suited for other small rotor-bearing system. As an example, the response due to a momentarily created unbalance is calculated. The nonlinear motion patterns of the pad and journal whirling orbit are obtained. Finally, the nonlinear orbit is compared to the linear one that could be calculated from linear stiffness and damping coefficients. It is shown that there are important differences between those two orbits and that the nonlinear simulation is more accurate.
\end{abstract}

Keywords: Tilting-pad guide bearing, Nonlinear oil film force, Hydro-unit, Computer numerical simulation

\section{INTRODUCTION}

With increasing size and performance of hydro-unit for power generation plants, knowledge of their behavior becomes more and more important. Basically, dynamic stability of the large hydro-unit is currently receiving a great deal of attention in literature since it influences the hydro-unit normal running directly. For example, in the Three Gorges Project, each hydro-unit's rated capacity reaches $700 \mathrm{MW}$, and its runner and guide bearing diameter are 10 and $3 \mathrm{~m}$ respectively. Especially, in order to determine design parameters (such as the number of guide bearings, radial clearance, supporting stiffness and journal's size, etc.), moreover, to evaluate the external exciting forces and deliver control tactics, it is indispensable to analyze the rotor system dynamic behavior accurately during the unit's design stage. Therefore, the dynamic behavior of rotor system is very important.

The large hydro-unit with a vertical arrangement is modeled in Fig. 1(a). From dynamics point of view, roter-bearing system of such machinery consists of shaft, generator rotor, water turbine, thrust bearings and seal rings, etc... For the sake of safety of the hydro-unit running, the critical speed, natural

*Corresponding author. Tel.: (029)3268130. E-mail: e974511@bull2.xjtu.edu.cn. 
(a)

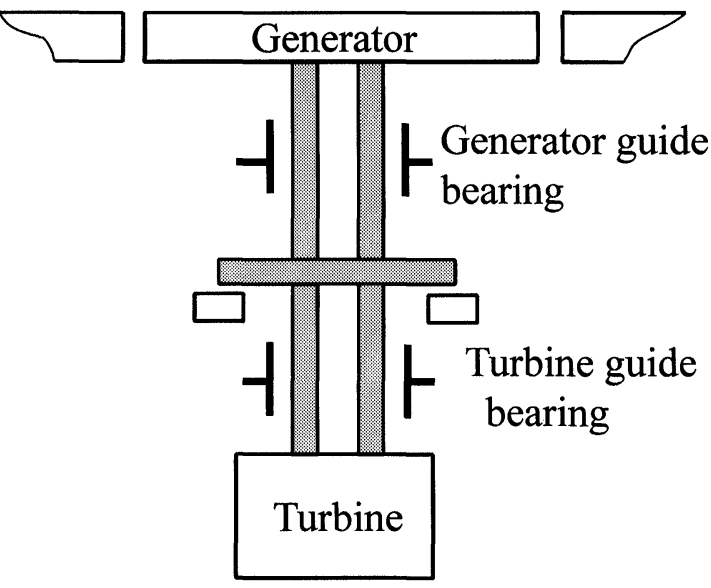

FIGURE 1(a) The model of hydro-unit.

frequency, and dynamic response of rotor system in lateral vibration would be important. All these respects have a close relation with the oil film dynamic behavior. The guide bearing, which serves as a support in radial direction, is not loaded static external force in radial direction in such vertical arrangement machinery, and the journal center should coincide with the bearing center in theory. It is well known that the stiffness and damping coefficients of the bearing perhaps are very small under previous conditions especially in the small pre-load bearing. So that, the displacement and velocity response of rotor system are perhaps comparable large as external excitation force is small. Sometime the Francis type hydraulic turbine would suffer a large lateral hydraulic excitation force when it is running on part load. This excitation force would make the center of journal whirl with a large amplitude. The linear theory is unsuitable for this situation. Consequently, we should look guide bearing film force as nonlinear function of journal center's displacement and velocity, pads' swing angles and angular velocities.

\section{THEORETICAL ANALYSIS}

\section{Methods to Obtain Nonlinear Film Force}

(a) Approximate method (Furkawa et al., 1994; Wang and Zhang, 1993). Reynolds equation is reduced by using long or short bearing assumption or using nonlinear coefficients that are defined as linear oil film model.

(b) Database method (Wang and Zhang, 1993). The database of non-stationary oil film force of bush segment has been set up and used to provide bush segment non-stationary oil film forces for assembling up the bearing nonlinear forces.

(c) Numerical simulation method (Cardinali et al., 1993; Gadangi et al., 1996; Monmousseau et al., 1997; Brancati et al., 1995). Non-stationary Reynolds equation is solved in the transient moving state of journal center of a specific bearing.

The first method reduced so much that it could not be satisfied with the need of the more accurate nonlinear analysis although its computation speed is fast. Both the accuracy and speed of the second method are better, but it only suits the fixed multilobe bearing at present. The accuracy and suitability of the third method are good, but it requires solving Reynolds equation many times and consumes large CPU-time in every time step. For this reason, the former simulations are only confined to the cylindrical journal bearing. However, in a long run, with the computer's hardware speed raising and software's functions improving, the shortcoming of numerical simulation will be dismissed gradually. The computer simulation process of nonlinear oil film force of tilting-pad guide bearing in large hydro-unit is presented in this paper.

\section{The Rotor's Kinetic Equation}

Figure 1(b) is examined and the coordinate system used. It consists of a massless rigid shaft carrying a disk with mass $(2 m)$ at the middle of the span, and two identical tilting-pad bearings supported at both ends of the shaft respectively. The external lateral excitation force $2 f(t)$ acts on the middle of the span, and $f(t)=f_{x}(t) \vec{i}+f_{y}(t) \vec{j}, f(t)$ is a known function of time. The equations of the journal center motion 


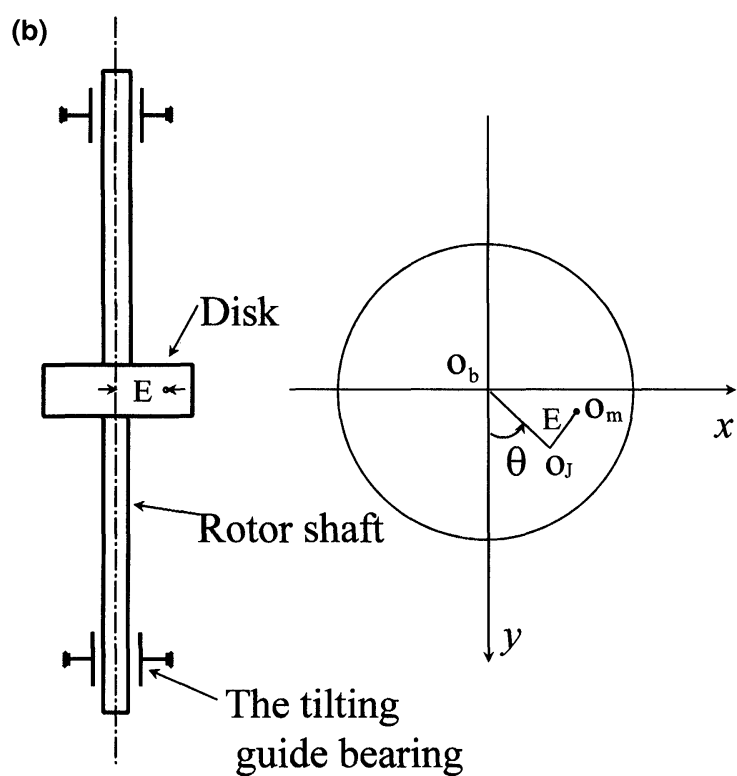

FIGURE 1(b) The model of the rotor.

can be described as:

$$
\left\{\begin{array}{l}
m \ddot{x}=-F_{x}+f_{x} \\
m \ddot{y}=-F_{y}+f_{y}
\end{array}\right.
$$

where, $\ddot{x}$ and $\ddot{y}$ are accelerations of journal center in $x$ - and $y$-directions respectively. $F_{x}, F_{y}$ are the film forces in $x$-and $y$-directions, which can be obtained by integration of the oil film pressure:

$$
\begin{aligned}
& F_{x}=\sum_{i=1}^{N} \int_{0}^{L} \int_{\varphi_{\text {in }}}^{\varphi_{\text {out }}} p \cos \varphi R \mathrm{~d} \varphi \mathrm{d} z, \\
& F_{y}=\sum_{i=1}^{N} \int_{0}^{L} \int_{\varphi_{\text {in }}}^{\varphi_{\text {out }}} p \sin \varphi R \mathrm{~d} \varphi \mathrm{d} z,
\end{aligned}
$$

where, $p$ is film distributing pressure on the pad, $L$ is pad length, $R$ is pad radius, $\varphi$ and $z$ are coordinates in circumferential direction and axial direction, $F_{x}$ and $F_{y}$ are the functions of $x, \dot{x}, y, \dot{y}, \delta_{i}, \dot{\delta}_{i}$, i.e.,

$$
\left\{\begin{array}{l}
F_{x}=F_{x}\left(x, \dot{x}, y, \dot{y}, \delta_{i}, \dot{\delta}_{i}\right) \\
F_{y}=F_{y}\left(x, \dot{x}, y, \dot{y}, \delta_{i}, \dot{\delta}_{i}\right) .
\end{array}\right.
$$

\section{Reynolds Equation}

In order to calculate the journal bearing force, the distribution pressure $p$ on the pad has to be determined, while $p$ must satisfy non-stationary Reynolds equation and Reynolds boundary condition (2.4). Due to its complexity, the Reynolds equation is usually solved numerically. Here the finite element method (FEM) is used in this work. A large number of grid nodes is necessary to get an accurate solution.

$$
\left\{\begin{array}{l}
\frac{1}{r} \frac{\partial}{\partial \varphi}\left(\frac{h^{3}}{12 \mu} \frac{1}{r} \frac{\partial p}{\partial \varphi}\right)+\frac{\partial}{\partial z}\left(\frac{h^{3}}{12 \mu} \frac{\partial p}{\partial z}\right)=\frac{1}{2} U \frac{\partial h}{r \partial \varphi}+\frac{\partial h}{\partial t} \\
p=0 \quad(z=0 \text { or } z=L) \\
p=0, \quad \frac{\partial p}{\partial \varphi}=0 \text { (at oil film rupture boundary) }
\end{array}\right.
$$

Because the journal diameter is very large, journal speed is low, and radius clearance is small, the Reynolds number of fluid in the clearance is much lower than its critical value. So that, Eq. (2.4) is laminary flow equation assumed. Non-dimension non-stationary Reynolds equation can be deduced as (2.4b) and coordinate system is used as Fig. 1(c):

$$
\begin{aligned}
\begin{array}{r}
u_{\varphi \varphi}- \\
=
\end{array} & \left(\frac{H^{3}}{\mu^{*}}\right)^{-1 / 2}\left\{6 \frac{\partial H}{\partial \varphi} \beta+12[-\varepsilon \overline{\dot{\theta}} \sin (\varphi-\theta)\right. \\
& \left.\left.-\overline{\dot{\varepsilon}} \cos (\varphi-\theta)-\frac{\overline{\dot{\delta}} \sin \left(\varphi-\tau_{0}\right)}{\psi_{\min }}\right]\right\}, \\
\beta= & \left.1+\varepsilon \overline{\dot{\theta}} \psi_{\min } \cos (\varphi-\theta)-\overline{\mathrm{\varepsilon}}\right) \\
& +\overline{\dot{\delta}}\left(1+\cos \left(\varphi-\tau_{0}\right)\right), \\
& 3\left[\left(\frac{H_{\varphi}}{H}\right)^{2}+2 \frac{H_{\varphi \varphi}}{H}-2 \frac{H_{\varphi}}{H} \frac{\mu_{\varphi}^{*}}{\mu^{*}}+\left(\frac{\mu_{\varphi}^{*}}{\mu^{*}}\right)^{2}-\frac{2}{3} \frac{\mu_{\varphi \varphi}^{*}}{\mu^{*}}\right],
\end{aligned}
$$

where,

$$
\begin{aligned}
\overline{\dot{\theta}} & =\frac{\mathrm{d} \theta}{\mathrm{d}(\omega t)}, \quad \overline{\dot{\varepsilon}}=\frac{\mathrm{d} \varepsilon}{\mathrm{d}(\omega t)}, \quad \psi_{\min }=\frac{\Delta R}{r}, \\
H & =\frac{h}{\Delta R}, \quad \mu^{*}=\frac{\mu}{\mu_{0}},
\end{aligned}
$$




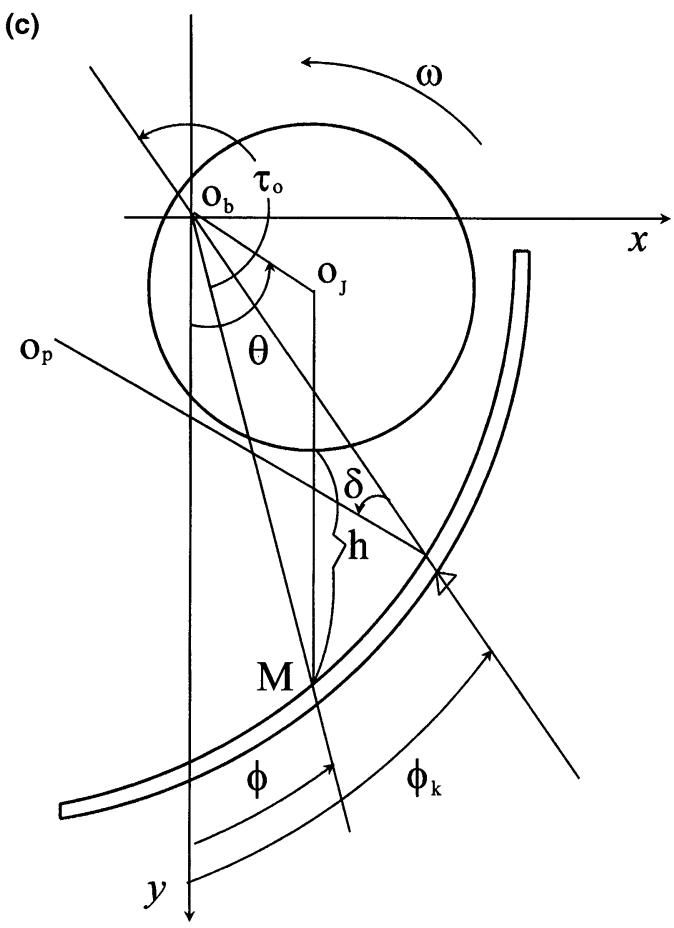

FIGURE 1(c) The geometrical relation between the rotor and one pad.

$$
\begin{aligned}
\varepsilon & =\frac{e}{\Delta R}, \overline{\dot{\delta}}=\frac{\mathrm{d} \delta}{\mathrm{d}(\omega t)}, u=\left(\frac{H^{3}}{\mu^{*}}\right)^{1 / 2} \frac{P \psi_{\min }^{2}}{\mu_{0} \omega}, \\
\bar{Z} & =\frac{z}{L}
\end{aligned}
$$

Since $\varepsilon \leq 1, \psi_{\min } \sim\left(10^{-3}-10^{-4}\right), \overline{\dot{\delta}} \sim \psi_{\min } \overline{\dot{\varepsilon}}, \overline{\dot{\theta}}$ does not exceed 10 and $\overline{\dot{\varepsilon}}$ is not too large in common, so that:

$$
\beta \approx 1
$$

\section{The Pad's Kinetic Equation}

Due to each tilting-pad is allowed to pitch about its pivot point, the pads' motion equation can be gained as follows:

$$
J_{0} \ddot{\delta}_{i}=M_{i} \quad(i=1,2,3, \ldots, N)
$$

where, $J_{0}$ is pad moment of inertia, $M_{i}$ is the moment of the fluid film pressure upon the pad about pivot point. Because $J_{0}$ can be quite small, $J_{0} \ddot{\delta}_{i}$ could be neglected, and (2.5) can be rewritten as:

$$
M_{i}=0 \quad(\mathrm{i}=1,2,3, \ldots, N) .
$$

\section{The Process of Nonlinear Oil-film Force Computer Simulation}

Equation (2.6) can be used to determine the tiltingpad' swing angles. The purpose of nonlinear film force simulation is to find the nonlinear function in Eq. (2.3) in numerical form. The process of simulation is to resolve the simultaneous Eqs. (2.1), (2.4) and (2.6) in turn.

Selecting proper initial condition is one key step in the simulation process. It is assumed that the initial position of the journal center is always in its static equilibrium position. Thus, the initial film force $\left(F_{x 0}, F_{y 0}\right)$, the initial position of the journal center $\left(x_{0}, y_{0}\right)$, and initial pad' angles $\delta_{i 0}$ $(i=1,2,3, \ldots, N)$, can be obtained by solving the static Reynolds Eq. (2.4) and pad balanced Eq. (2.6). It should be pointed out that the journal center moving velocity and each pad's swing velocity are zero under these circumstances. Now, all the initial conditions of Eqs. (2.1) and (2.4) can be written as:

$$
\left\{\begin{array}{l}
t=0, \\
F_{x}=F_{x_{0}}, \quad F_{y}=F_{y_{0}}, \\
x=x_{0}, \quad y=y_{0}, \quad \dot{x}=\dot{y}=0 \\
\delta_{i}=\delta_{i 0}, \quad \dot{\delta}_{i 0}=0
\end{array}\right.
$$

Equation (2.7) could express the initial conditions while the journal center equilibrium position is disturbed abruptly by an impact load, such as earthquake, magnetic pull failure or sudden partial mass failures.

The steps of simulation are presented as:

(a) Obtain the initial conditions by resolving static Reynolds equation and equilibrium equations of pads.

(b) Increase a time step $\Delta t\left(t_{j}=t_{j-1}+\Delta t\right)$, and calculate the exciting force $\left(f_{x}, f_{y}\right)_{j}$ at this time.

(c) Solve the motion Eq. (2.1) by use of $\left(f_{x}, f_{y}\right)_{j}$ and film force at previous step $\left(F_{x}, F_{y}\right)_{j-1}$, 
$(x, \dot{x}, y, \dot{y})_{j}$ can be calculated, and denoted them as $(x, \dot{x}, y, \dot{y})_{j}^{(1)}$.

(d) Take $\left(\delta_{i}, \dot{\delta}_{i}\right)_{j-1}$ as initial values and solve the simultaneous Eqs. (2.4) and (2.6), obtain $\left(F_{x}\right.$, $\left.F_{y}\right)_{j}^{(1)},\left(\delta_{i}\right)_{j}$ and $\left(\dot{\delta}_{i}\right)_{j}=\left[\left(\delta_{i}\right)_{j}^{(1)}-\left(\delta_{i}\right)_{j-1}\right] / \Delta t$.

(e) Modify $(x, \dot{x}, y, \dot{y})_{j}^{(1)}$, with implicit method and obtain $(x, \dot{x}, y, \dot{y})_{j}^{(2)}$, and then, to judge whether the accuracy is satisfied, if not, let $(x, \dot{x}, y, \dot{y})_{j}^{(2)} \Rightarrow(x, \dot{x}, y, \dot{y})_{j}^{(1)}$ and return to the (d) step.

(f) Repeat (b), (c), (d), (e), steps in turns until the $t$ reach to $t_{0}$ that has been specified.

According to the former simulation course, we have completed the nonlinear film force calculation program. The diagram of calculation procedure is shown in Fig. 2. A systematic study shows that it is necessary to set a convergence $(\|\Delta S / S\|)$ criterion of $10^{-4}$ for motion varies. For higher values of the

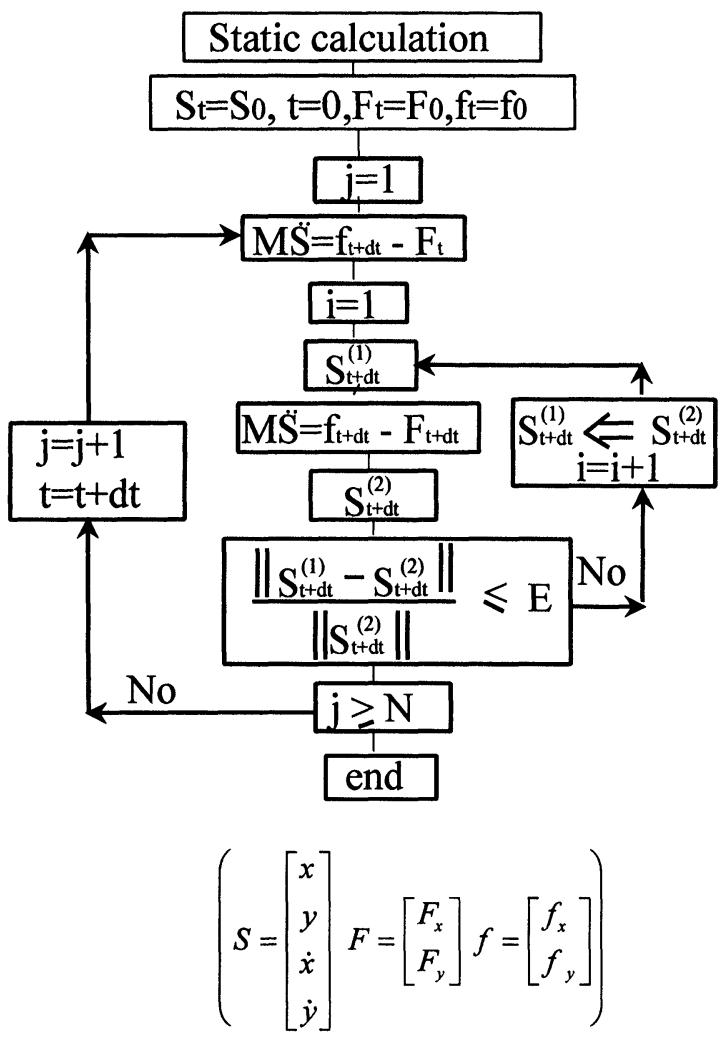

FIGURE 2 The diagram of calculation procedure. criterion, numerical instabilities appear and convergence of the $S$ is not achieved; using more severe convergence criteria provides no significant improvement in the final results, but the CPU-time greatly increase.

\section{NUMERICAL EXAMPLES}

In order to investigate the relationship between nonlinear film forces $\left(F_{x}, F_{y}\right)$ and variables $x, \dot{x}$, $y, \dot{y}, \delta_{i}, \dot{\delta}_{i}$, the water turbine guide bearing and generator guide bearing of a $240 \mathrm{MW}$ hydro-unit have been simulated respectively. The turbine guide bearing has 10 shoes $\left(\psi_{v}=1\right)$ and the generator guide bearing has 12 shoes $\left(\psi_{v}=119.4\right)$. They represent two kinds of typical tilting-pad bearings in large Francis hydro-unit. For the sake of the simplicity and convenience, we take a momentarily created unbalanced mass force as excitation force:

$$
\begin{aligned}
f & =f_{x} \vec{i}+f_{y} \vec{j}, \\
& =M E \omega^{2}(\sin \omega t \vec{i}+\cos \omega t \vec{j}),
\end{aligned}
$$

where, $E$ is equivalent mass eccentricity, $\omega$ is angle velocity of the journal. Substitution of Eq. (3.1) into (2.1), obtains

$$
\begin{aligned}
& \ddot{\bar{X}}=-a \bar{F}_{x}+\xi \sin \bar{t} \\
& \ddot{\bar{Y}}=-a \bar{F}_{y}+\xi \cos \bar{t}
\end{aligned}
$$

where,

$$
\begin{aligned}
\bar{X} & =x / c, \quad \xi=E / c, \quad \bar{F}_{x}=F_{x} / a \\
\bar{F}_{y} & =F_{y} / a, \quad a=\frac{2 \mu L}{\psi_{\min }^{3} M \omega}, \\
\bar{t} & =\omega t, \quad \psi_{\min }=c / r, \quad D=2 R, \quad \psi_{v}=\frac{R_{p}-r}{c}
\end{aligned}
$$

The numerical time-integration of the motion of the journal center and calculation of the film force are performed according to Eqs. (3.2) and (2.4b) respectively. The parameter values of bearings are presented in Tables I and II. 
Furthermore, a comparison of the nonlinear simulation with a linear one is carried out under the same operating conditions. In the linear simulation, the dynamic coefficients of bearing are calculated at the center of the bearing and listed in Table III.

TABLE I The parameters of turbine bearing

\begin{tabular}{rrrr}
\hline Pad no. & \multicolumn{1}{c}{$\varphi_{\text {in }}$} & \multicolumn{1}{c}{$\varphi_{\text {out }}$} & $\tau$ \\
\hline 1 & -8.77 & 8.77 & 180 \\
2 & 27.23 & 44.77 & 216 \\
3 & 63.23 & 80.77 & 252 \\
4 & 99.23 & 116.77 & 288 \\
5 & 135.23 & 152.77 & 324 \\
6 & 171.23 & 188.77 & 360 \\
7 & 207.23 & 224.77 & 36 \\
8 & 243.23 & 260.77 & 72 \\
9 & 276.23 & 296.77 & 108 \\
10 & 315.2 & 332.77 & 144 \\
\hline
\end{tabular}

$\psi_{\min }=1.27 \times 10^{-4}, \psi_{v}=1, L / D=0.175, \beta=0.5$ $M=376.9 \mathrm{t}, \mu_{0}=0.0045 \mathrm{~kg} \cdot \mathrm{s} / \mathrm{m}^{2}, \omega=68.18 \mathrm{rpm}$, $D=2360 \mathrm{~mm}, \xi=29.4, c=0.15 \mathrm{~mm}$.

TABLE II The parameters of generator guide bearing

\begin{tabular}{lrrr}
\hline Pad no. & \multicolumn{1}{c}{$\varphi_{\text {in }}$} & $\varphi_{\text {out }}$ & $\tau$ \\
\hline 1 & -12.57 & 12.57 & 180 \\
2 & 17.43 & 42.57 & 210 \\
3 & 47.43 & 72.57 & 240 \\
4 & 77.43 & 102.57 & 270 \\
5 & 107.43 & 132.57 & 300 \\
6 & 137.43 & 162.57 & 330 \\
7 & 167.43 & 192.57 & 360 \\
8 & 197.43 & 222.57 & 30 \\
9 & 227.43 & 252.57 & 60 \\
10 & 257.43 & 282.57 & 90 \\
11 & 287.43 & 312.57 & 120 \\
12 & 317.43 & 342.57 & 150 \\
\hline
\end{tabular}

$\psi_{\min }=2.12 \times 10^{-4}, \psi_{v}=119.44, L / D=0.235, \beta=0.5$ $M=945.9 \mathrm{t}, \mu_{0}=0.0045 \mathrm{~kg} \cdot \mathrm{s} / \mathrm{m}^{2}, \omega=68.18 \mathrm{rpm}, D=$ $1700 \mathrm{~mm}, \xi=4.9, c=0.18 \mathrm{~mm}$

TABLE III The non-dimensional coefficients of generator bearing

\begin{tabular}{lccc}
\hline Kxx & Kyy & Cxx & Cyy \\
\hline 0.08166 & 0.08166 & 0.00866 & 0.00866 \\
\hline
\end{tabular}

When $\varepsilon=0$.

\section{RESULTS AND DISCUSSION}

1. Pre-load $\left(\psi_{v}\right)$ influences the hydro-unit's behavior largely. In Figs. 3(a) and 4(a), it is shown that the pre-load $\left(\psi_{v}\right)$ of bearing influence on the swing angle and velocity of the pad largely. The generator guide bearing's pad swing angle--time $(\delta-T)$ curve is obviously different from that of the water turbine bearing's.

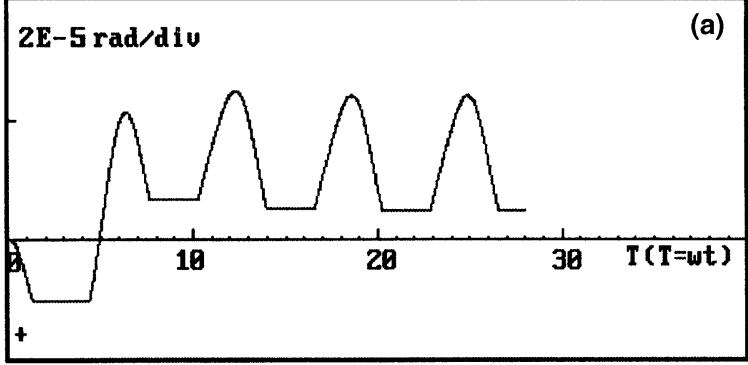

FIGURE 3(a) One of the water turbine guide bearing's pad swing angle versus time curve $\left(\delta_{i}-T\right)$.

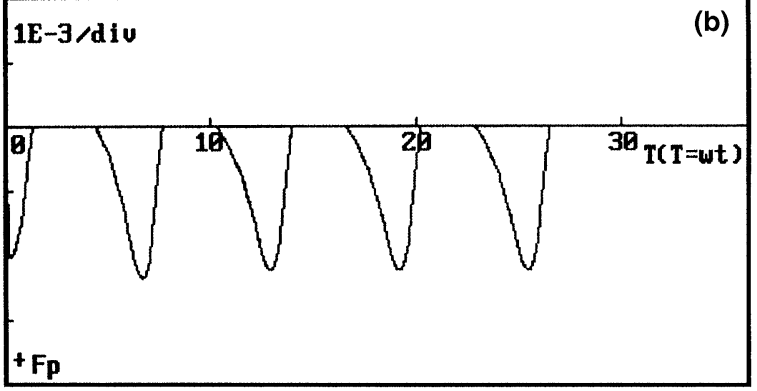

FIGURE 3(b) One of the water guide bearing's pad resultant force versus time curve $\left(F_{\mathrm{p}}-T\right)$.

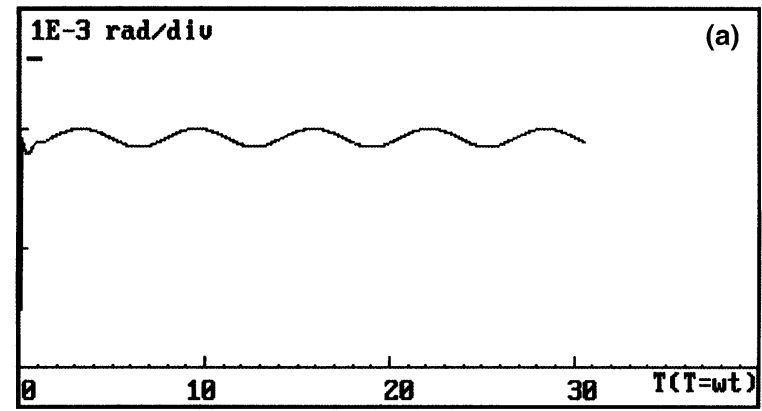

FIGURE 4(a) One of the generator guide bearing's pad swing angle versus time curve $\left(\delta_{i}-T\right)$. 


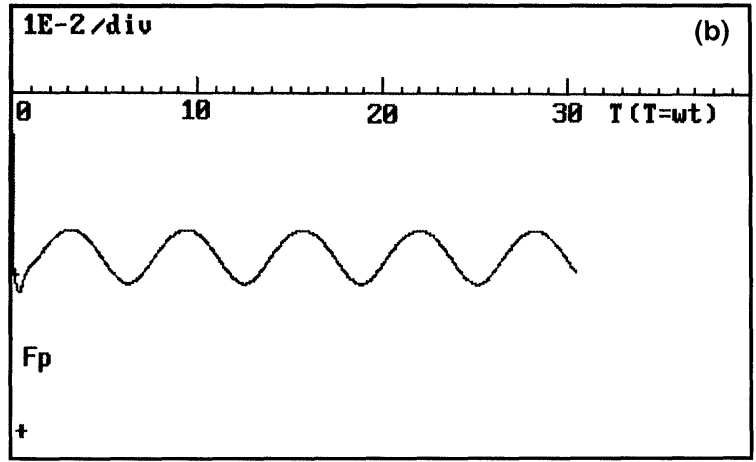

FIGURE 4(b) One of the generator guide bearing's pad resultant force versus time curve $\left(F_{\mathrm{p}}-T\right)$.

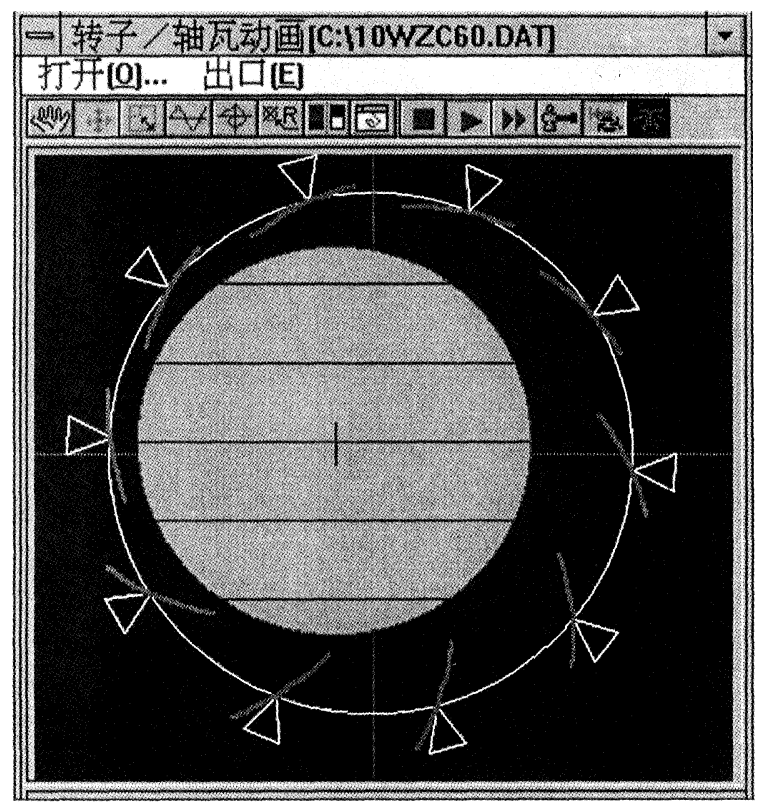

FIGURE 5 Display of the result of simulation.

Moreover, we can deduce that there are half of the pads of the water turbine guide bearing reacting on the shaft from Figs. 3(a) or 5, and all pads of the generator guide bearing reacting on the shaft from Fig. 4(a). Figs. 3(b) and 4(b) are curves that show that the oil film force of single pad varies with time respectively. It is very interesting that the two curve forms are absolutely different for different preloads. Figure 6 shows the nonlinear whirling orbit of journal center of turbine guide bearing $\left(\psi_{v}=1\right)$.

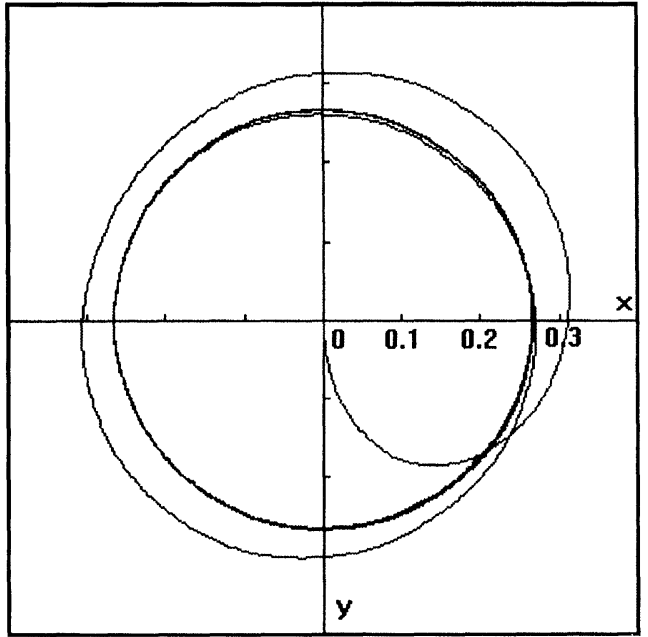

FIGURE 6 The nonlinear whirling orbit of the water guide bearing $\left(\psi_{v}=1\right)$.

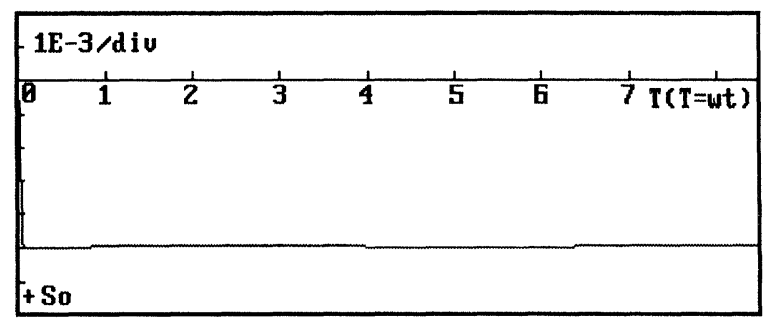

FIGURE 7 The resultant force versus time $(S 0-T)$ curve of the water guide bearing $\left(\psi_{v}=1\right)$.

The resultant of film force of each bearing is also presented, in Figs. $7\left(\psi_{\nu}=1\right)$ and 8 $\left(\psi_{v}=119.4\right)$. It can be seen that their convergence trends are different.

2. Difference between the results, which are calculated by linear and nonlinear method respectively, is large. It should be noted that all the dynamic coefficients are equal to zero at the point of center of the turbine bearing $\left(\psi_{v}=1\right)$ in theory. Therefore, even as the excitation force on the journal is small, the displacement and velocity of journal center will be comparatively large, and linearization may lead to errors. For generator guide bearing $\left(\psi_{v}=119.4\right)$, the linear and nonlinear whirling orbits are almost identical perfectly when a small force is imposed on the journal. (see Figs. 9(a) and 9(b)). But, as the 


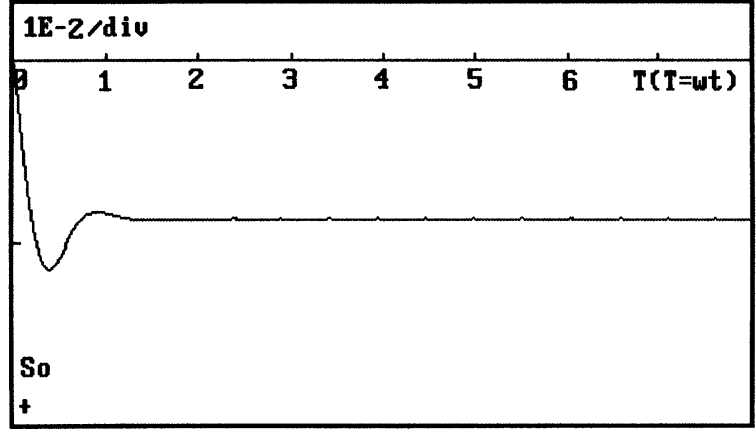

FIGURE 8 The resultant force versus time $(S 0-T)$ curve of the generator guide bearing $\left(\psi_{v}=119.4\right)$.

(a)

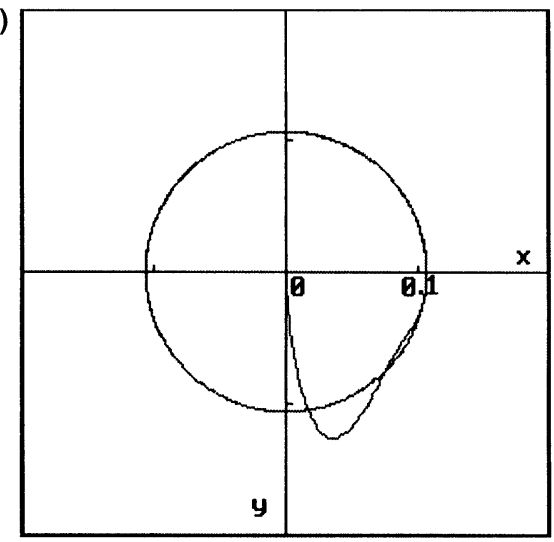

FIGURE 9(a) The linear whirling orbit of the generator guide bearing $\left(\psi_{v}=119.4\right)$ under small external force.

(b)

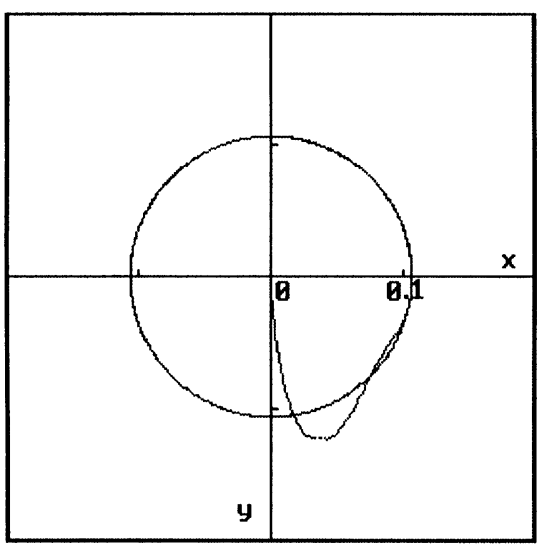

FIGURE 9(b) The nonlinear whirling orbit of the generator guide bearing $\left(\psi_{\nu}=119.4\right)$ under small external force (c)

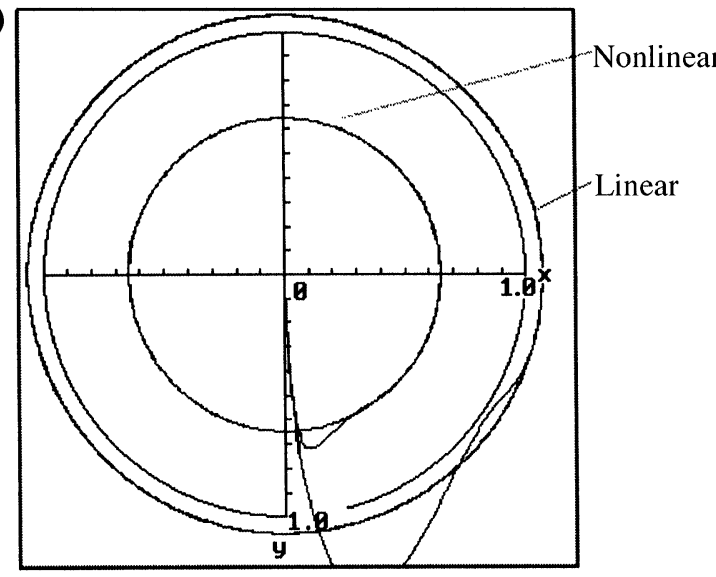

FIGURE 9(c) The linear and nonlinear whirling orbit of the generator guide bearing $\left(\psi_{v}=119.4\right)$ under same larger external force.

force amplitude increases to a value big enough to make the radius of nonlinear whirling orbit reach to about 0.75 , there is a distinct difference between these two. The linear result is wrong visibly (see Fig. 9(c)). Of course, the dynamic responses computed by nonlinear simulation appear to be more accurate and realistic. However, the nonlinear simulations spend more CPU-time than the linear.

3. In the other point of view, when the external force is small, the linear and nonlinear whirling orbit are almost equal. When the external force is larger, the linear and nonlinear whirling orbit become larger, but the linear is larger than nonlinear. All these results proved that the nonlinear results are correct reasonably.

\section{CONCLUSIONS}

1. On the basis of the non-stationary Reynolds equation and nonlinear theory, the paper investigates the nonlinear oil film forces of tiltingpad guide bearing in large hydro-unit. There is difference between the tilting-pad guide bearings' oil film forces that can be calculated by linear and nonlinear methods. It is important to analyze the bearing when pre-load is small 
(especially, to pre-load $\psi_{v}=1$ ) by nonlinear method.

2. The pre-load $\left(\psi_{v}=1\right)$ of the tilting-pad bearing is a crucial factor which influence the hydro-unit largely.

3. At present, for the nonlinear film force theory is not perfect, in order to deal with the nonlinear film force of tilting guide bearing in actual engineering, the numerical simulation method is an effective way.

\section{NOMENCLATURE}

$\begin{array}{ll}L & \text { pad length } \\ D & \text { journal diameter } \\ \Delta R(\text { or } c) & \text { radius clearance } \\ \mu & \text { viscosity of the oil } \\ R & \text { radius of bearing } \\ r & \text { radius of journal } \\ R_{\mathrm{p}} & \text { radius of pad }\end{array}$

time

tilting-pad angle $i=1,2,3, \ldots, N(N$ : total number of pads)

\section{References}

Brancati, R., Rocca, E., Russo, M. and Russo, R. (1995) Journal orbits and their stability for rigid unbalanced rotors, $A S M E$ Journal of Lubrication Technology, 117, 709-716.

Cardinali, R., Nordmann, R. and Sperber, A. (1993) Dynamic simulation of non-linear models of hydroelectric machinery, Mechanical Systems and Signal Processing, 7, 29-44.

Furkawa, T., Matsumoto, I. and Esaki, J. (1994) Nonlinear analysis of dynamic characteristics of cylindrical bearing oil film, Trans., JSME, series C, 60(571), 292-298.

Gadangi, R.K., Palazzolo, A.B. and Kim, J. (1996) Transient analysis of plain and tilt pad journal bearings including fluid film temperature effects, ASME Journal of Lubrication Technology, 118, 423-430.

Monmousseau, P., Fillon, M. and Frene, J. (1997) Transient thermoelastohydrodynamic study of tilting-pad journal bearings - comparison between experimental data and theoretical results, ASME Journal of Lubrication Technology, 119, 409-407.

Wang, W. and Zhang, Z. (1993) Nonlinear oil film force database, Journal of Shanghai University of Technology, 14, 12-17. 


\section{ait \\ ENERGY MATERIALS}

M A N E Y publishing

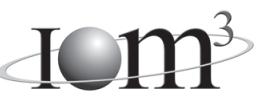

\section{Materials Science \& Engineering for Energy Systems}

Maney Publishing on behalf of the Institute of Materials, Minerals and Mining

The Institute of Materials, Minerals \& Mining

Economic and environmental factors are creating ever greater pressures for the efficient generation, transmission and use of energy. Materials developments are crucial to progress in all these areas: to innovation in design; to extending lifetime and maintenance intervals; and to successful operation in more demanding environments. Drawing together the broad community with interests in these areas, Energy Materials addresses materials needs in future energy generation, transmission, utilisation, conservation and storage. The journal covers thermal generation and gas turbines; renewable power (wind, wave, tidal, hydro, solar and geothermal); fuel cells (low and high temperature); materials issues relevant to biomass and biotechnology; nuclear power generation (fission and fusion); hydrogen generation and storage in the context of the 'hydrogen economy'; and the transmission and storage of the energy produced.

As well as publishing high-quality peer-reviewed research, Energy Materials promotes discussion of issues common to all sectors, through commissioned reviews and commentaries. The journal includes coverage of energy economics and policy, and broader social issues, since the political and legislative context influence research and investment decisions.

\section{CALL FOR PAPERS}

Contributions to the journal should be submitted online at http://ema.edmgr.com

To view the Notes for Contributors please visit: www.maney.co.uk/journals/notes/ema

Upon publication in 2006, this journal will be available via the Ingenta Connect journals service. To view free sample content online visit: www.ingentaconnect.com/content/maney

For further information please contact:

Maney Publishing UK

Tel: +44 (0)113 2497481 Fax: +44 (0)1132486983 Email: subscriptions@maney.co.uk

or

Maney Publishing North America

Tel (toll free): 8662975154 Fax: 6173546875 Email: maney@maneyusa.com

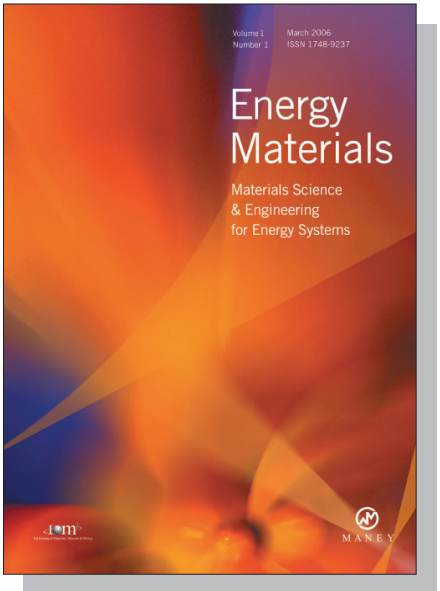

EDITORS

Dr Fujio Abe

NIMS, Japan

Dr John Hald, IPL-MPT, Technical University of Denmark, Denmark

Dr R Viswanathan, EPRI, USA

\section{SUBSCRIPTION INFORMATION}

Volume 1 (2006), 4 issues per year

Print ISSN: 1748-9237 Online ISSN: 1748-9245

Individual rate: $£ 76.00 / U S \$ 141.00$

Institutional rate: $£ 235.00 /$ US $\$ 435.00$

Online-only institutional rate: $£ 199.00 / U S \$ 367.00$

For special $\mathrm{IOM}^{3}$ member rates please email

subscriptions@maney.co.uk

\section{For further information or to subscribe online please visit www.maney.co.uk}



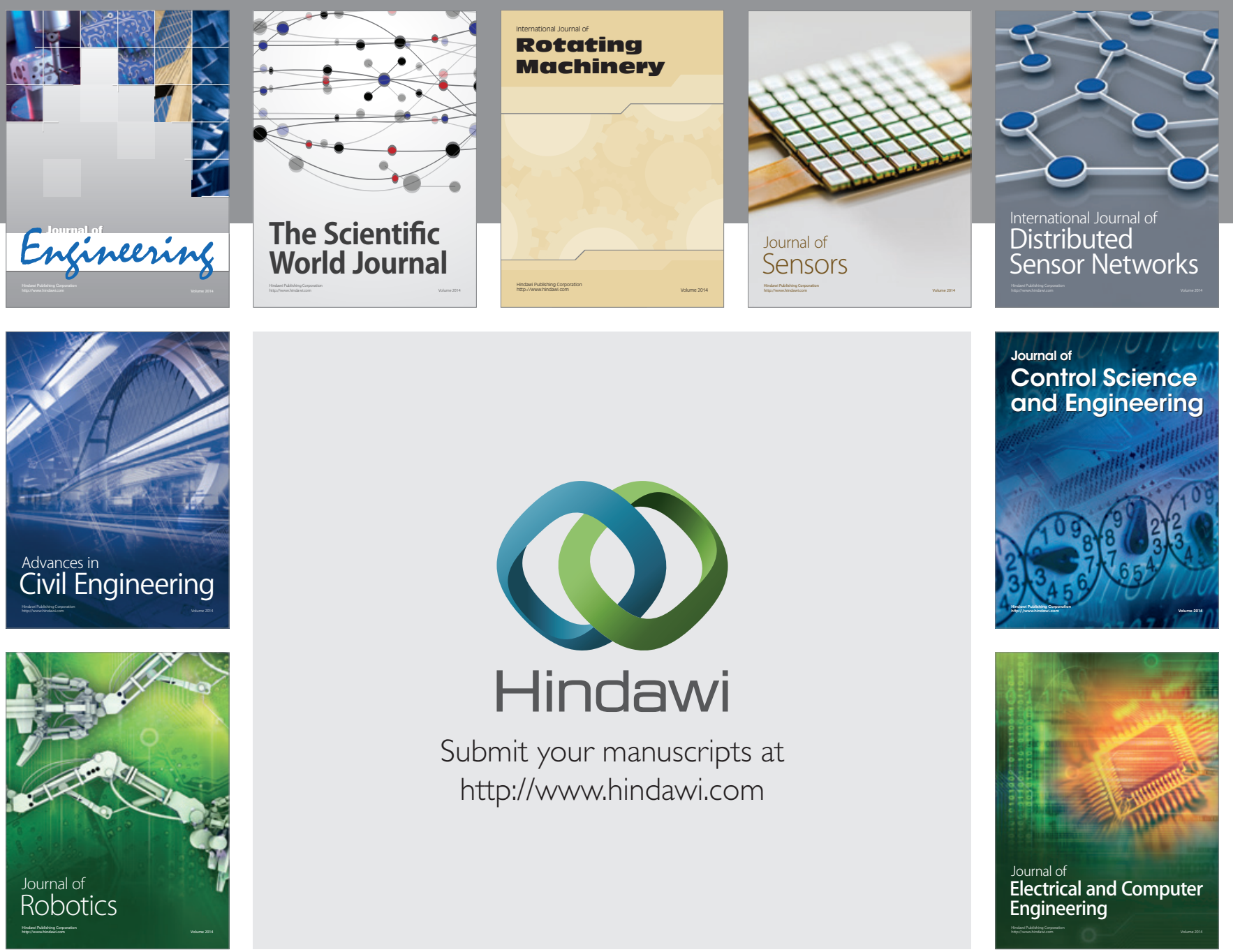

Submit your manuscripts at

http://www.hindawi.com
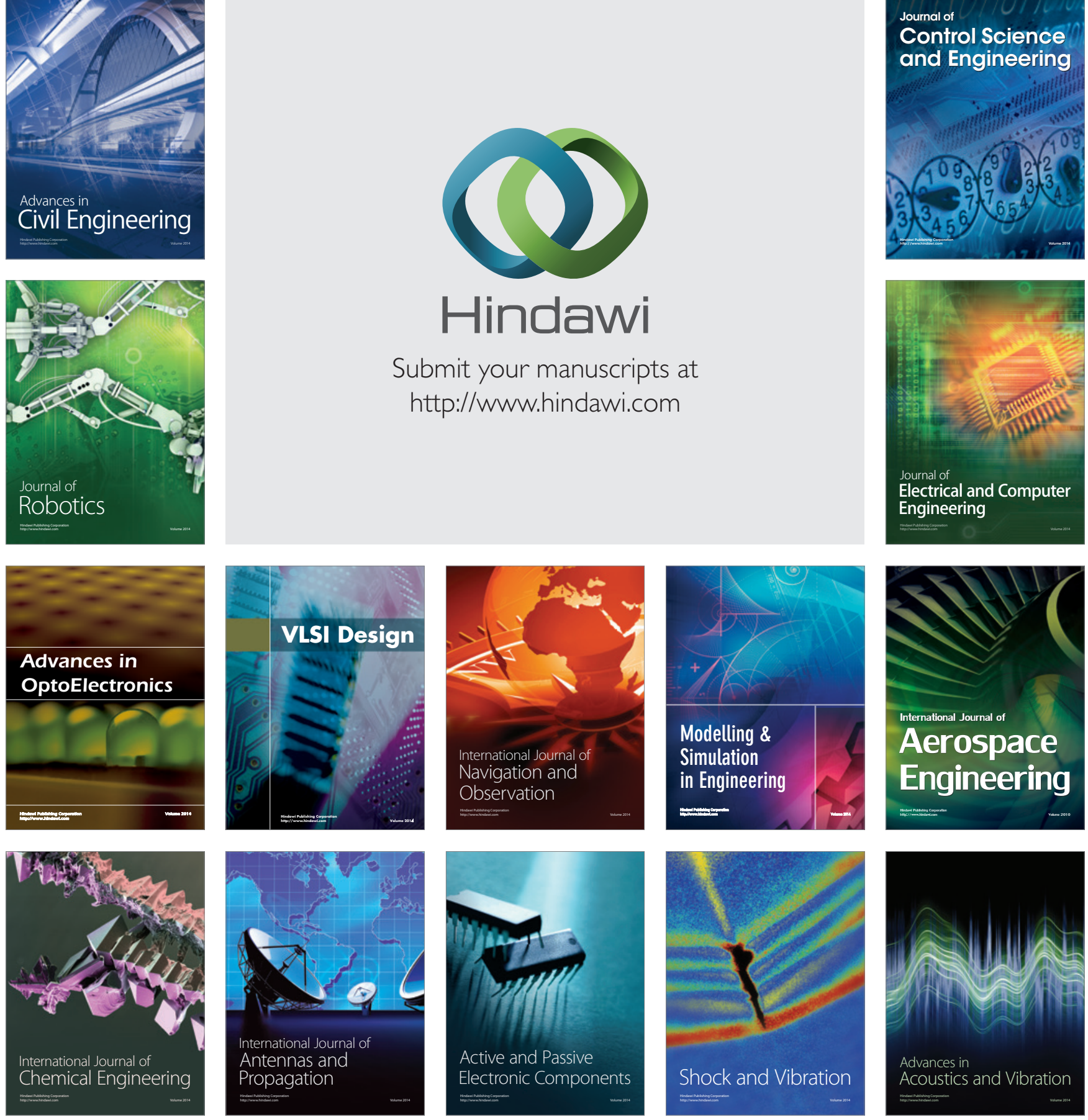